\title{
A Disease-specific Score for Estimating Survival After Irradiation of Bone Metastases from Colorectal Cancer
}

\author{
RAPHA HAUS ${ }^{1}$, STEFAN JANSSEN $^{1,2}$, STEVEN E. SCHILD $^{3}$ and DIRK RADES ${ }^{1}$ \\ ${ }^{1}$ Department of Radiation Oncology, University of Lübeck, Lübeck, Germany; \\ ${ }^{2}$ Medical Practice for Radiotherapy and Radiation Oncology, Hannover, Germany; \\ ${ }^{3}$ Department of Radiation Oncology, Mayo Clinic, Scottsdale, AZ, U.S.A.
}

\begin{abstract}
Background/Aim: Estimating survival is important for treatment personalization in patients with metastatic cancer. In this study, we aimed to develop a survival score for patients irradiated for bone metastases from colorectal cancer. Patients and Methods: Eleven factors were retrospectively analyzed in 25 patients, including age, gender, Eastern Cooperative Oncology Group performance score, tumor site, time between diagnosis of colorectal cancer and irradiation, visceral or other bone metastases, type and number of irradiated sites, upfront surgery and previous systemic treatment. Results: On multivariate analysis, performance score $(p=0.005)$ and previous systemic treatment $(p=0.007)$ were significantly associated with survival and used for the score. One point (performance score $0-1$ or no previous systemic treatment) or 0 points (performance score $\geq 2$ or previous systemic treatment) were assigned resulting in 0,1 or 2 points. Six-month survival rates of these groups were 0\%, 64\% and $100 \%$, respectively. Conclusion: This new survival score can support physicians during personalization of treatment for patients with bone metastases from colorectal cancer.
\end{abstract}

Due to improved treatment of primary tumors and locoregional recurrences, many cancer patients have better survival prognoses and may live long enough to experience metastatic spread (1). For these patients, personalized treatment approaches have become more popular during the last decade aiming to meet the personal needs of an individual patient. The remaining lifetime is an important aspect that needs to be

Correspondence to: Professor Dirk Rades, MD, Department of Radiation Oncology, University of Lübeck, Ratzeburger Allee 160, 23562 Lübeck, Germany. Tel: +49 45150045401, Fax: +49 45150045404, e-mail: rades.dirk@gmx.net

Key Words: Colorectal cancer, bone metastases, radiotherapy, survival, prognostic score. considered when designing a personalized treatment concept. For patients with a short survival time, the treatment regimen should be little burdensome and as short as reasonably possible. For patients with more favorable prognoses, longerterm local control and prevention of late treatment-related toxicities become more important. Estimation of the survival prognosis of an individual patient may be considerably facilitated with survival scores. In order to allow for an optimal personalization of a treatment program for cancer patients with metastatic disease, specific scores should ideally be available for the different metastatic sites and the different primary tumor types. Colorectal cancer is one of the most common primary tumor types in industrial nations (1). Bone metastases from colorectal cancer are comparatively rare and require more attention $(1,2)$. The present study was performed to develop a specific survival score for colorectal cancer patients with bone metastases.

\section{Patients and Methods}

Twenty-five patients who were treated with radiotherapy for bone metastases from colorectal cancer without spinal cord compression were included in the present study. Their data were retrospectively analyzed to identify significant prognostic factors of survival following radiotherapy and develop a prognostic score. The study has been approved by the local ethics committee. Radiotherapy was administered as a multi-fraction treatment with either $6 \times 4$ Gy $(n=1)$, $10 \times 3$ Gy $(n=5), 12 \times 3$ Gy $(n=1), 14-15 \times 2.5$ Gy $(n=16), 15 \times 2$ Gy $(n=1)$ or $20 \times 2.0$ Gy $(n=1)$. In this cohort, eleven factors (Table I) were evaluated for a potential impact on survival, including i) age ( $\leq 65 v s . \geq 66$ years), ii) gender, iii) Eastern Cooperative Oncology Group (ECOG) performance score $(0-1 v s . \geq 2)$ (3), iv) primary tumor site (colon $v s$. rectum), v) time between diagnosis of colorectal cancer and radiotherapy for bone metastases ( $\leq 12 v s . \geq 13$ months, median=12 months), vi) visceral metastases (no $v s$. yes), vii) other bone metastases (no $v s$. yes), viii) type of metastatic sites (spinal vs. extraspinal vs. both), ix) number of irradiated sites of bone metastases ( $1 v s . \geq 2), \mathrm{x})$ upfront surgery of irradiated bone metastases (no vs. yes) and xi) systemic treatment prior to irradiation (no $v s$. yes). 
Survival was calculated since the first day of radiotherapy. Univariate analyses of survival were performed using the KaplanMeier method and the log-rank test. Factors that proved to be significant $(p<0.05)$ or showed at least a trend $(p<0.10)$ on univariate analyses were included in the multivariate analysis (Cox proportional hazards model). Those factors achieving significance in the multivariate analysis were used for the development of the prognostic score.

\section{Results}

In the entire cohort, the median follow-up time was 4 months (range $=0-65$ months). The survival rates at 3, 6, 9 and 12 months were $56 \%, 44 \%, 32 \%$ and $23 \%$, respectively. On univariate analyses, a better (0-1) ECOG performance score $(p=0.005)$, absence of other bone metastases $(p=0.001)$ and a lower number $(n=1)$ of irradiated sites of bone metastases $(p=0.049)$ were significantly associated with favorable survival prognoses. In addition, no systemic treatment prior to radiotherapy showed a trend for a favorable survival $(p=0.067)$. The results of the univariate analyses are shown in Table II.

On multivariate analysis, the ECOG performance score [hazard ratio $(\mathrm{HR})=6.97,95 \%$ confidence interval $(\mathrm{CI})=1.75$ 36.34, $p=0.005$ ] and the systemic treatment prior to radiotherapy $(\mathrm{HR}=7.50,95 \% \mathrm{CI}=1.64-60.17, p=0.007)$ were significant. Other bone metastases $(\mathrm{HR}=2.05,95 \% \mathrm{CI}=0.51$ $9.74, p=0.32$ ) and the number of irradiated sites of bone metastases $(\mathrm{HR}=1.25,95 \% \mathrm{CI}=0.35-4.54, p=0.73) \mathrm{did}$ not achieve significance in the multivariate analysis.

Thus, the ECOG performance score and the systemic treatment prior to radiotherapy were used for the development of the scoring tool. Based on the outcomes with respect to survival, 1 point (favorable outcome: ECOG performance score of $0-1$ or no previous systemic treatment) or 0 points (unfavorable outcome: ECOG performance score of $\geq 2$ or previous systemic treatment) were assigned resulting in three prognostic groups of 0 points $(n=7), 1$ point $(n=11)$ or 2 points $(n=2)$. The survival data of the three groups are shown in Table III and Figure 1.

\section{Discussion}

Many patients with metastatic colorectal cancer have a comparatively poor survival (1). A considerable number of studies regarding this situation, including application of novel anti-cancer agents, have been performed during recent years to improve the prognoses of these patients (4-9). In addition, the use of personalized treatment programs taking into account individual patients' lifespans may contribute to the improvement of their prognoses. The design of such programs can be considerably facilitates with the application of specific survival scores. A considerable number of patients with metastatic colorectal cancer receive radiotherapy,
Table I. Factors evaluated for a potential impact on survival.

\begin{tabular}{|c|c|}
\hline & Number of patients $(\%)$ \\
\hline \multicolumn{2}{|l|}{ Age at RT } \\
\hline$\leq 65$ Years & $11(44)$ \\
\hline$\geq 66$ Years & $14(56)$ \\
\hline \multicolumn{2}{|l|}{ Gender } \\
\hline Female & $10(40)$ \\
\hline Male & $15(60)$ \\
\hline \multicolumn{2}{|c|}{ ECOG performance score } \\
\hline $0-1$ & $11(44)$ \\
\hline$\geq 2$ & $9(36)$ \\
\hline Unknown & $5(20)$ \\
\hline \multicolumn{2}{|l|}{ Tumor site } \\
\hline Colon & $16(64)$ \\
\hline Rectum & $9(36)$ \\
\hline \multicolumn{2}{|c|}{$\begin{array}{l}\text { Interval between diagnosis of colorectal } \\
\text { cancer and RT of bone metastases }\end{array}$} \\
\hline$\leq 12$ Months & $13(52)$ \\
\hline$\geq 13$ Months & $12(48)$ \\
\hline \multicolumn{2}{|c|}{ Visceral metastases } \\
\hline No & $2(8)$ \\
\hline Yes & $23(92)$ \\
\hline \multicolumn{2}{|c|}{ Other bone metastases } \\
\hline No & $12(48)$ \\
\hline Yes & $13(52)$ \\
\hline \multicolumn{2}{|c|}{ Type of metastatic sites } \\
\hline Spinal & $9(36)$ \\
\hline Extraspinal & $12(48)$ \\
\hline Both & $4(16)$ \\
\hline \multicolumn{2}{|c|}{ Number of irradiated sites } \\
\hline 1 & $14(56)$ \\
\hline$\geq 2$ & $11(44)$ \\
\hline \multicolumn{2}{|c|}{ Upfront surgery of bone metastases } \\
\hline No & $21(84)$ \\
\hline Yes & $4(16)$ \\
\hline \multicolumn{2}{|c|}{ Systemic treatment prior to RT } \\
\hline No & $5(20)$ \\
\hline Yes & $20(80)$ \\
\hline
\end{tabular}

RT: Radiotherapy; ECOG: Eastern Cooperative Oncology Group.

particularly for brain and bone metastases. Prognostic factors have already been identified and specific survival scores already exist for colorectal cancer patients with brain metastases or metastatic spinal cord compression (10-16). However, no specific survival score has been available so far for patients with colorectal cancer irradiated for bone metastases without compression of the spinal cord, hence the purpose of the present study. All patients included in this study received multi-fraction radiotherapy with an overall treatment time longer than one week. Longer-course multifraction radiotherapy is the standard regimen for bone metastases in the contributing centers. Short-course radiotherapy with an overall treatment time of one week or less is generally limited to patients with an extremely poor survival prognosis. Therefore, patients treated with short- 
Table II. Survival rates of the 11 potential prognostic factors (univariate analysis).

\begin{tabular}{|c|c|c|c|c|c|}
\hline \multirow[t]{2}{*}{ Factor } & \multicolumn{4}{|c|}{ Survival rates (in \%) at } & \multirow[t]{2}{*}{$p$-Value } \\
\hline & 3 months & 6 months & 9 months & 12 months & \\
\hline \multicolumn{6}{|l|}{ Age at RT } \\
\hline$\leq 65$ Years & 64 & 55 & 45 & 45 & \\
\hline$\geq 66$ Years & 50 & 36 & 21 & 7 & 0.15 \\
\hline \multicolumn{6}{|l|}{ Gender } \\
\hline Female & 60 & 60 & 50 & 38 & \\
\hline Male & 53 & 33 & 20 & 13 & 0.61 \\
\hline \multicolumn{6}{|c|}{ ECOG performance score } \\
\hline $0-1$ & 73 & 64 & 55 & 44 & \\
\hline$\geq 2$ & 33 & 22 & 11 & 0 & 0.005 \\
\hline \multicolumn{6}{|l|}{ Tumor site } \\
\hline Colon & 50 & 38 & 23 & 16 & \\
\hline Rectum & 67 & 56 & 44 & 33 & 0.11 \\
\hline \multicolumn{6}{|c|}{$\begin{array}{l}\text { Time between diagnosis of colorectal } \\
\text { cancer and RT of bone metastases }\end{array}$} \\
\hline$\leq 12$ Months & 69 & 54 & 37 & 37 & \\
\hline$\geq 13$ Months & 42 & 33 & 25 & 8 & 0.17 \\
\hline \multicolumn{6}{|c|}{ Visceral metastases } \\
\hline No & 100 & 100 & 100 & 100 & \\
\hline Yes & 52 & 39 & 26 & 17 & 0.18 \\
\hline \multicolumn{6}{|c|}{ Other bone metastases } \\
\hline No & 67 & 67 & 67 & 48 & \\
\hline Yes & 46 & 23 & 0 & 0 & 0.001 \\
\hline \multicolumn{6}{|c|}{ Type of metastatic sites } \\
\hline Spinal & 56 & 44 & 33 & 22 & \\
\hline Extraspinal & 58 & 50 & 31 & 21 & \\
\hline Both & 50 & 25 & 25 & 25 & 0.69 \\
\hline \multicolumn{6}{|c|}{ Number of irradiated sites } \\
\hline 1 & 57 & 57 & 49 & 33 & \\
\hline$\geq 2$ & 55 & 27 & 9 & 9 & 0.049 \\
\hline \multicolumn{6}{|c|}{ Upfront surgery of bone metastases } \\
\hline No & 57 & 43 & 28 & 22 & \\
\hline Yes & 50 & 50 & 50 & 25 & 0.91 \\
\hline \multicolumn{6}{|c|}{ Systemic treatment prior to RT } \\
\hline No & 100 & 100 & 53 & 27 & \\
\hline Yes & 45 & 30 & 25 & 20 & 0.067 \\
\hline
\end{tabular}

RT: Radiotherapy; ECOG: Eastern Cooperative Oncology Group; bold $p$-value: significant.

Table III. Survival rates of the three prognostic groups.

\begin{tabular}{|c|c|c|c|c|c|}
\hline \multirow[t]{2}{*}{ Prognostic group } & \multicolumn{4}{|c|}{ Survival rates (in \%) at } & \multirow[t]{2}{*}{$p$-Value } \\
\hline & 3 months & 6 months & 9 months & 12 months & \\
\hline 0 Points & 14 & 0 & 0 & 0 & \\
\hline 1 Point & 73 & 64 & 45 & 27 & \\
\hline 2 Points & 100 & 100 & 100 & 100 & $<0.001$ \\
\hline
\end{tabular}

Bold $p$-value: significant.

course radiotherapy were not included to avoid a selection bias due to the dose-fractionation program.

Based on two independent prognostic factors of survival, i.e. ECOG performance score and systemic treatment prior to radiotherapy, a scoring tool has been designed that includes three prognostic groups. Of those patients with 0 points, only $14 \%$ survived for 3 months and no patient for 6 months or more. These patients should be strongly considered for single- 


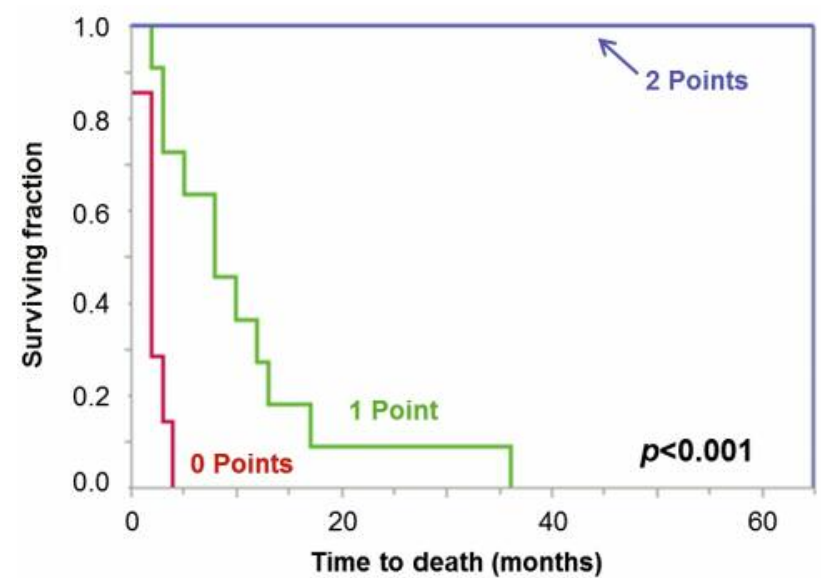

Figure 1. Kaplan-Meier curves for the survival of the three prognostic groups ( 0 points, 1 point and 2 points). The p-value was obtained using the log-rank test.

fraction radiotherapy if they have symptoms, such as bone pain, that need to be relieved. According to a meta-analysis of randomized trials, single-fraction radiotherapy with $1 \times 8$ Gy is as effective as multi-fraction regimens, mainly $10 \times 3$ Gy for two weeks, with respect to pain relief (17). Patients treated with $1 \times 8$ Gy require re-irradiation in the same region significantly more often compared to patients receiving multi-fraction radiotherapy. However, patients of the present study with 0 points have such a short remaining life time that they are unlikely to live long enough to experience recurrent bone pain in the irradiated regions. Patients achieving 1 point had a better survival prognosis; $64 \%$ survived for 6 months and 27\% for 12 months. Thus, a considerable proportion of this group will live long enough to be at risk of developing a local recurrence of the irradiated bone metastases. If these patients have uncomplicated painful bone metastases without a (pending) pathological fracture or a large soft tissue component, they may also be treated with $1 \times 8 \mathrm{~Gy}$, since a local recurrence can be successfully treated with another single fraction of radiotherapy $(18,19)$. In case of a (pending) pathological fracture or a large soft tissue component, the patients appear better treated with longer-course radiotherapy, e.g. $10 \times 3 \mathrm{~Gy}$ in two weeks, which was shown to result in a better re-calcification of the osteolytic bone compared to $1 \times 8 \mathrm{~Gy}(20)$. Patients with 2 points had very favorable prognoses; all patients survived for at least 12 months. Since the risk of a local recurrence increases with lifetime, these patients should be considered for longer-course radiotherapy with higher doses, such as $14-15 \times 2.5$ Gy for three weeks and $20 \times 2$ Gy for four weeks. These dose-fractionation regimens have already been recommended for patients with favorable survival prognoses and vertebral metastases associated with symptomatic compression of the spinal cord $(12,14,20,21)$. When following these recommendations, the limitations of this study, including the retrospective design and the small number of patients, must be regarded. Moreover, since patients receiving single-fraction or short-course multi-fraction radiotherapy were not included, the recommendations may not be generalized to these patients.

In conclusion, this new scoring tool includes three prognostic scores with significantly different survival prognoses. It can support physicians during the process of personalization of the radiation treatment for patients with bone metastases from colorectal cancer.

\section{Conflicts of Interest}

On behalf of all Authors, the corresponding author states that there are no conflicts of interest related to this study.

\section{Authors' Contributions}

R.H., S.J., S.E.S and D.R. participated in the design of the study. R.H., S.J. and D.R. provided data. D.R. and S.E.S. performed the analyses of the data. R.H. and D.R drafted the manuscript, which has been reviewed and approved by all authors.

\section{References}

1 Siegel RL, Miller KD and Jemal A: Cancer statistics, 2019. CA Cancer J Clin 69: 7-34, 2019. PMID: 30620402. DOI: 10.3322/caac. 21551

2 Rades D, Schild SE and Abrahm JL: Treatment of painful bone metastases. Nat Rev Clin Oncol 7: 220-229, 2010. PMID: 20234353. DOI: 10.1038 /nrclinonc.2010.17

3 Oken MM, Creech RH, Tormey DC, Horton J, Davis TE, McFadden ET and Carbone PP: Toxicity and response criteria of the Eastern Cooperative Oncology Group. Am J Clin Oncol 5: 649-655, 1982. PMID: 7165009.

4 Lehtomaki KI, Lahtinen LI, Rintanen N, Kuopio T, Kholova I, Makela R, Rantala JK, Kellokumpu-Lehtinen PL and Kononen J: Clonal evolution of MEK/MAPK pathway activating mutations in a metastatic colorectal cancer case. Anticancer Res 39: 5867-5877, 2019. PMID: 31704811. DOI: 10.21873/anticanres.13791

5 Fiala O, Ostasov P, Hosek P, Sorejs O, Liska V, Buchler T, Poprach A, Kucera R, Topolcan O, Sustr J, Sedivcova M and Finek J: The predictive role of primary tumour sidedness in metastatic colorectal cancer treated with targeted agents. Anticancer Res 39: 5645-5652, 2019. PMID: 31570462. DOI: 10.21873/anticanres.13761

6 Morine Y, Ikemoto T, Iwahashi S, Saito YU, Yamada S, Takasu C, Higashijima J, Imura S and Shimada M: Clinical impact of FOLFOXIRI aiming for conversion surgery in unresectable multiple colorectal liver metastasis. Anticancer Res 39: 50895096, 2019. PMID: 31519620. DOI: 10.21873/anticanres.13703

7 Shibutani M, Nagahara H, Fukuoka T, Iseki Y, Hirakawa K and Ohira M: Efficacy of adjuvant chemotherapy according to the classification of recurrence risk based on systemic inflammatory markers in patients with liver metastases of colorectal cancer. Anticancer Res 39: 5039-5045, 2019. PMID: 3151961. DOI: 10.21873/anticanres.13695 
8 Kearney MR, Chen EY, Vaccaro GM, Strother J, Burt A, Todd K, Donovan J, Kampa-Schittenhelm KM and Lopez CD: A phase II study alternating erlotinib with second-line mFOLFOX6 or FOLFIRI for metastatic colorectal cancer. Anticancer Res 39: 245252, 2019. PMID: 30591465. DOI: 10.21873/anticanres.13104

9 Li A, Käsmann L, Rades D and Fu C: A scoring system to predict the development of bone metastasis after radical resection of colorectal cancer. Anticancer Res 37: 5169-5172, 2017. PMID: 28870950. DOI: 10.21873/anticanres.11938

10 Rades D, Hansen HC, Janssen S and Schild SE: Diagnosis-specific WBRT-30-CRC score for estimating survival of patients irradiated for brain metastases from colorectal cancer. Anticancer Res 39: 2569-2574, 2019. PMID: 31092454. DOI: 10.21873/anticanres. 13379

11 Rades D, Dziggel L, Blanck O, Gebauer N, Bartscht T and Schild SE: A score to identify patients with brain metastases from colorectal cancer who may benefit from whole-brain radiotherapy in addition to stereotactic radiosurgery/radiotherapy. Anticancer Res 38: 3111-3114, 2018. PMID: 29715148. DOI: 10.21873/ anticanres. 12570

12 Rades D, Bartscht T, Janssen S, Bajrovic A, Segedin B and Schild SE: Forecasting survival probabilities after radiotherapy of metastatic epidural spinal cord compression from colorectal cancer in the elderly. Anticancer Res 36: 1829-1833, 2016. PMID: 27069166.

13 Rades D, Dahlke M, Gebauer N, Bartscht T, Hornung D, Trang NT, Phuong PC, Khoa MT and Gliemroth J: A new predictive tool for optimization of the treatment of brain metastases from colorectal cancer after stereotactic radiosurgery. Anticancer Res 35: 5515-5518, 2015. PMID: 26408718.

14 Dziggel L, Segedin B, Podvrsnik NH, Oblak I, Schild SE and Rades D: A survival score for patients with brain metastases from less radiosensitive tumors treated with whole-brain radiotherapy alone. Strahlenther Onkol 190: 54-58, 2014. PMID: 23861153. DOI: $10.1007 / \mathrm{s} 00066-013-0394-2$

15 Rades D, Douglas S, Huttenlocher S, Veninga T, Bajrovic A, Rudat V and Schild SE: Prognostic factors and a survival score for patients with metastatic spinal cord compression from colorectal cancer. Strahlenther Onkol 188: 1114-1118, 2010. PMID:23111468. DOI:10.1007/s00066-012-0141-0
16 Meyners T, Heisterkamp C, Kueter JD, Veninga T, Stalpers LJ, Schild SE and Rades D: Prognostic factors for outcomes after whole-brain irradiation of brain metastases from relatively radioresistant tumors: a retrospective analysis. BMC Cancer 10: 582, 2010. PMID: 20977700. DOI: 10.1186/1471-2407-10-582

17 Chow E, Zeng L, Salvo N, Dennis K, Tsao M and Lutz S: Update on the systematic review of palliative radiotherapy trials for bone metastases. Clin Oncol (R Coll Radiol) 24: 112-124, 2012. PMID: 22130630. DOI: 10.1016/j.clon.2011.11.004

18 Mithal NP, Needham PR and Hoskin PJ: Retreatment with radiotherapy for painful bone metastases. Int J Radiat Oncol Biol Phys 29: 1011-1014, 1994. PMID: 7521863. DOI: 10.1016/03603016(94)90396-4

19 Huisman M, van den Bosch MA, Wijlemans JW, van Vulpen M, van der Linden YM and Verkooijen HM: Effectiveness of reirradiation for painful bone metastases: a systematic review and meta-analysis. Int J Radiat Oncol Biol Phys 84: 8-14, 2012. PMID: 22300568. DOI: 10.1016/j.ijrobp.2011.10.080

20 Koswig S and Budach V: Remineralization and pain relief in bone metastases after after different radiotherapy fractions (10 times 3 Gy vs. 1 time 8 Gy). A prospective study. Strahlenther Onkol 175: 500-508, 1999. PMID: 10554645. DOI: 10.1007/s000660050061

21 Rades D, Douglas S, Veninga T, Stalpers LJ, Hoskin PJ, Bajrovic A, Adamietz IA, Basic H, Dunst J and Schild SE: Validation and simplification of a score predicting survival in patients irradiated for metastatic spinal cord compression. Cancer 116: 3670-3673, 2010. PMID: 20564129. DOI: 10.1002/cner.25223

22 Rades D and Abrahm JL: The role of radiotherapy for metastatic epidural spinal cord compression. Nat Rev Clin Oncol 7: 590598, 2010. PMID: 20808299. DOI: 10.1038/nrclinonc.2010.137

Received November 23, 2019

Revised November 28, 2019

Accepted December 2, 2019 